\title{
Avoiding maternal vitamin D deficiency may lower blood glucose in pregnancy
}

\author{
Méabh Walsh \\ Technological University Dublin \\ Linnea Bärebring \\ University of Gothenburg \\ Hanna Augustin \\ University of Gothenburg, hanna.augustin@gu.se
}

Follow this and additional works at: https://arrow.tudublin.ie/schfsehart

Part of the Food Science Commons, Maternal and Child Health Commons, Maternal, Child Health and Neonatal Nursing Commons, and the Women's Health Commons

\section{Recommended Citation}

Meabh Walsh, Linnea Bärebring, Hanna Augustin, Avoiding maternal vitamin D deficiency may lower blood glucose in pregnancy, The Journal of Steroid Biochemistry and Molecular Biology, Volume 186, 2019, Pages 117-121, ISSN 0960-0760, DOI: 10.1016/j.jsbmb.2018.10.003.

This Article is brought to you for free and open access by the School of Food Science and Environmental Health at ARROW@TU Dublin. It has been accepted for inclusion in Articles by an authorized administrator of ARROW@TU Dublin. For more information, please contact arrow.admin@tudublin.ie, aisling.coyne@tudublin.ie, gerard.connolly@tudublin.ie.

Funder: Swedish Research Council for Health, Working

Life and Welfare; Healthcare sub-committee, Region

Västra Götaland; Linnea and Josef Carlsson Foundation;

Queen Silvia's Jubilee Fund

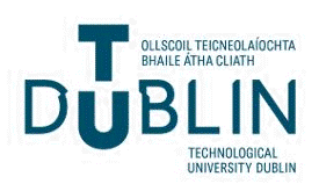




\title{
Avoiding maternal vitamin D deficiency may lower blood glucose in pregnancy
}

\author{
Meabh Walsh ${ }^{\mathrm{a}, \mathrm{b}}$, Linnea Bärebring ${ }^{\mathrm{a}}$, Hanna Augustin ${ }^{\mathrm{a}, *}$ \\ a Department of Internal Medicine and Clinical Nutrition, Sahlgrenska Academy, University of Gothenburg, Sweden \\ ${ }^{\mathbf{b}}$ Dublin Institute of Technology, Trinity College Dublin, Ireland
}

\section{A R T I C L E I N F O}

\section{keywords:}

Hyperglycaemia

Large for gestational age

25-hydroxyvitamin D

\begin{abstract}
A B S T R A C T
Background: Vitamin D status is hypothesised to play a role in gestational glucose control. No studies to date have examined vitamin D in relation to changes in blood glucose in pregnancy. Thus, the aim was to examine if vitamin D in early pregnancy and vitamin D trajectory associate with blood glucose trajectory over pregnancy in a Swedish cohort. We also investigated the relation between maternal vitamin D status and excessive fetal growth.

Methods: In 2013-2014, pregnant women were recruited to the GraviD cohort study when registering at the antenatal clinics in south-west Sweden. In the present analysis, 1928 women were included. Women with preexisting diabetes and multifetal pregnancy were excluded. Random blood glucose was assessed according to routine practice, in first trimester (T1, gestational week 4-16), second trimester (T2, gestational week 17-27), early (T3a, gestational week 28-35) and late third trimester (T3b, gestational week 36-41). In T1 and T3a, serum 25-hydroxyvitamim D (25OHD) was analyzed by liquid chromatography tandem mass spectrometry. Large for gestational age (LGA), as a proxy of excessive fetal growth, was defined as body weight at birth above 2 standard deviations of the gender specific population mean. Adjusted linear regression, linear mixed models analysis and logistic regression analysis were used to study 25OHD in relation to T1 blood glucose, glucose trajectory and LGA, respectively.

Results: Mean blood glucose increased during pregnancy $(5.21 \mathrm{mmol} / \mathrm{L}$ in T1, $5.27 \mathrm{mmol} / \mathrm{L}$ in T2, $5.31 \mathrm{mmol} / \mathrm{L}$ in T3a and $5.34 \mathrm{mmol} / \mathrm{L}$ in T3b; $\mathrm{p}=0.003$ ). In T1, 25OHD was negatively associated with blood glucose, i.e. $25 \mathrm{OHD} \geq 30 \mathrm{nmol} / \mathrm{L}$ was associated with $0.25-0.35 \mathrm{mmol} / \mathrm{L}$ lower glucose. T1 $25 \mathrm{OHD}$ was also negatively associated with blood glucose trajectory. Higher T3 25OHD was associated with higher odds of LGA $(p=0.032)$. Conclusion: Avoiding maternal vitamin D deficiency in early pregnancy is associated with lower blood glucose in early pregnancy and throughout pregnancy. Higher 25OHD in late pregnancy was associated with higher odds of LGA at birth.
\end{abstract}

\section{Introduction}

Global estimates from 2013 indicate that 21.4 million live births were affected by hyperglycaemia in pregnancy [1]. It is well-established that increased glycaemia creates an unfavourable environment for embryonic and foeto-placental development [2]. For example, results from the large Hyperglycemia and Adverse Pregnancy Outcomes (HAPO) study shows a continuous graded relationship between higher maternal blood glucose concentration and increasing frequency of serious neonatal and maternal complications, including increased risk of large for gestational age (LGA) infants [3].
Recent literature identifies a possible role of vitamin D as a modulator of gestational glucose control and hyperglycaemia in pregnancy, including gestational diabetes mellitus (GDM) [4,5]. Thus, the maternal vitamin D status may be important for gestational glucose control and of major clinical significance to maternal and neonatal health in pregnancy. Circulating concentrations of 25-hydroxyvitamin D (25OHD) in serum or plasma is the most widely used biomarker of vitamin D status [6]. Currently, there are no pregnancy-specific 25OHD thresholds to constitute vitamin D adequacy. Thus, cut-offs for the adult population are often adopted for pregnant women [7]. The Institute of Medicine define vitamin D deficiency as $25 \mathrm{OHD}$ concentrations $<30 \mathrm{nmol} / \mathrm{L}$ for

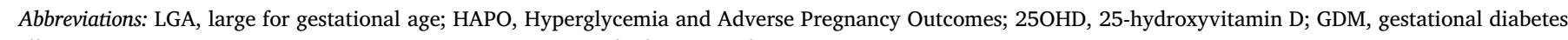
mellitus; T1, trimester 1; T2, trimester 2; T3, trimester 3; BMI, body mass index

* Corresponding author at: Box 459, SE-40530, Gothenburg, Sweden.

E-mail address: hanna.augustin@gu.se (H. Augustin).
} 
both the general and pregnant population [8]; a cut-off also adopted by Nordic nutrition recommendations [9]. In accordance with this cut-off, the prevalence of vitamin D deficiency is about $10 \%$ amongst pregnant women in Sweden in first trimester, with higher rates observed among women of African and Asian descent [10].

Poor vitamin D status is theorised to exacerbate insulin resistance and hyperglycaemia in the pregnant state via its involvement in pancreatic $\beta$-cell function [11], insulin sensitivity [12] and inflammation [13]. In non-diabetic pregnant cohorts, vitamin D deficiency has been inversely associated with altered glucose homeostasis including fasting glucose levels, post-prandial glucose levels, $\beta$-cell function and insulin resistance $[14,15]$. Individual observational studies and meta-analyses support the linkage between maternal vitamin D deficiency and GDM development [16-19]. These studies are however, cross-sectional in nature and predominantly examine the influence of vitamin D in the second trimester of pregnancy. Studies examining the effects of vitamin D status in first trimester on subsequent glucose metabolism are limited and the few studies available have produced disparate results [20-25].

Given the possible effects of vitamin D metabolism on glucose metabolism in pregnancy, it is likely that longitudinal changes in 25OHD in pregnancy (vitamin D trajectory) also have an important effect on glucose control throughout pregnancy (glucose trajectory). However, to our knowledge, no studies to date have examined the relation between vitamin D trajectory and blood glucose trajectory throughout pregnancy in either non-diabetic or diabetic cohorts.

Therefore, the objectives were to examine if maternal vitamin D in early pregnancy and vitamin D trajectory associate with blood glucose trajectory in pregnancy. We also investigated the relation between maternal vitamin D status and odds of having a LGA infant.

\section{Methods}

\subsection{Recruitment}

Women were invited to participate in the GraviD cohort study when registering for antenatal care in south-west of Sweden (within the regions Södra Bohuslän, Södra Älvsborg and Gothenburg) in autumn 2013 and spring 2014. The only exclusion criterion was pregnancy exceeding 16 weeks at registration. In the current analysis, 1928 women were included, after additionally exclusion of women with preexisting diabetes and multifetal pregnancies.

\subsection{Sample and data collection}

Women were sampled for random (not standardized for fasting and time during the day) blood glucose according to standard practice of care by finger prick puncture at four time points; at registration for antenatal care (T1, gestational weeks 4-16), in the second trimester of pregnancy (T2, gestational weeks 17-27), in early third trimester (T3a, gestational weeks 28-35) and late in the third trimester (T3b, gestational weeks 36-42). At T1 and T3a, women were also sampled for blood collection by venous puncture for analyses of serum 25OHD.

Questionnaires were used in T1 to collect data on ethnicity (country of birth, divided into North Europe, or non-North Europe), education level attained (primary, secondary of university level). Season at sampling was coded dichotomously as winter (November-April) or summer (May-October). Data on maternal body mass index (BMI), maternal age, gestational age and infant size at birth (as a proxy of fetal growth) were retrieved from the medical records. Infant birth size, was evaluated for LGA, defined as weight at birth above 2 standard deviations of the gender specific population mean, according to standard practice. Data on blood glucose and diagnosis of GDM were retrieved from the medical records.

\subsection{Laboratory analysis}

Blood glucose was measured in blood collected using a finger prick test method, according to standard practice. The HemoCue ${ }^{\circledR}$ Beta-glucose analyzer is the most commonly used point-of-care glucose monitoring device in antenatal care settings in Sweden.

Vitamin D status was measured as 25OHD concentration in serum using liquid tandem mass spectrometry by the central laboratory in the Region Skåne, Sweden. The laboratory is accredited by the Vitamin D External Quality Assessment Scheme. Details regarding laboratory analysis and blood sample handling was been described in detail [10].

\subsection{Statistical analysis}

A cross sectional analysis of the association between 250HD concentration and random blood glucose at registration in $\mathrm{T} 1$ for antenatal care was performed using linear regression analysis. Two mixed models analyses were used for investigating the associations between 25OHD concentration and blood glucose trajectory. Serum 25OHD was included as the independent variable either as 1) categorical 25OHD concentration at $\mathrm{T} 1$ or 2 ) continuous $25 \mathrm{OHD}$ trajectory. The 25OHD categories were $<30 \mathrm{nmol} / \mathrm{L}, 30-49.9 \mathrm{nmol} / \mathrm{L}, \quad 50-74.9 \mathrm{nmol} / \mathrm{L}$ and $\geq 75 \mathrm{nmol} / \mathrm{L}$. For the second model with $25 \mathrm{OHD}$ trajectory, 25OHD measured in $\mathrm{T} 1$ and T3a were included, along with the mean of T1 and T3a as a proxy for T2. T3a was duplicated as T3b to achieve the complete the continuous 25OHD trajectory. Blood glucose trajectory included concentrations at T1, T2, T3a and T3b. Both mixed models analyses used an autoregressive covariance matrix, as the correlations decreased with time. Associations between 25OHD concentration and LGA were assessed using logistic regression analysis. Confounders included in all analyses were maternal age, gestational age at enrolment, maternal T1 BMI, education, season at sampling and maternal ethnicity.

\section{Results}

In total, 1928 women were included in this analysis and their characteristics are described in Table 1. GDM was diagnosed in 11 women, and 40 infants were born LGA. Higher blood glucose in T1 was associated with significantly increased odds of GDM (OR $=1.949$, $\mathrm{p}<0.001$ ), but not with LGA (OR $=0.883, \mathrm{p}=0.383$ ).

Lower vitamin D status in T1 was associated with higher blood glucose, and those with T1 $25 \mathrm{OHD}$ concentration $\geq 30 \mathrm{nmol} / \mathrm{L}$ had $0.25-0.35 \mathrm{mmol} / \mathrm{L}$ lower blood glucose (depending on 25OHD category) than those with vitamin D deficiency (Table 2). Similarly, $25 \mathrm{OHD} \geq 30 \mathrm{nmol} / \mathrm{L}$ in T1, was associated with a lower glucose trajectory throughout pregnancy, compared to vitamin D deficient women (Table 3). Other significant determinants of higher glucose in $\mathrm{T} 1$ and higher glucose trajectory were higher maternal age, BMI and non-North European origin, while the associations were negative with gestational age in $\mathrm{T} 1$.

The 25OHD trajectory was not associated with glucose trajectory (Table 4). Significant determinants of higher glucose trajectory were higher maternal age and higher maternal T1 BMI, lower education and non-North European origin. Lower glucose trajectory was associated with higher gestational age at enrolment. 25OHD in T1 was not associated with LGA infant $(\mathrm{OR}=1.000, \mathrm{p}=0.991)$. However, 25OHD in T3 was significantly associated with higher odds of LGA and the odds increased by $6 \%$ for every $10 \mathrm{nmol} / \mathrm{L}$ increase in T3 25OHD (Table 5).

\section{Discussion}

In this longitudinal population based cohort study, we found that $25 \mathrm{OHD}$ concentrations $\geq 30 \mathrm{nmol} / \mathrm{L}$ in early pregnancy was associated with both lower early pregnancy blood glucose and with lower glucose trajectory in pregnancy. However, 25OHD trajectory was not associated with glucose trajectory, and higher vitamin D status in late pregnancy 
Table 1

Characteristics of the participating pregnant women.

\begin{tabular}{|c|c|c|c|}
\hline & $\mathrm{N}$ & Mean & Standard deviation \\
\hline Maternal age T1 (years) & 1928 & 31.5 & 4.9 \\
\hline Maternal BMI T1 $\left(\mathrm{kg} / \mathrm{m}^{2}\right)$ & 1907 & 24.4 & 4.1 \\
\hline Gestational week T1 & 1850 & 10.3 & 2.2 \\
\hline Gestational week T2 & 1826 & 25.2 & 0.9 \\
\hline Gestational week T3a & 1794 & 32.4 & 1.0 \\
\hline Gestational week T3b & 1717 & 37.4 & 0.8 \\
\hline Glucose T1 (mmol/L) & 1896 & 5.2 & 1.1 \\
\hline Glucose T2 (mmol/L) & 1785 & 5.3 & 1.1 \\
\hline Glucose T3a (mmol/L) & 1780 & 5.3 & 1.1 \\
\hline Glucose T3b (mmol/L) & 1684 & 5.3 & 1.1 \\
\hline 25OHD T1 (nmol/L) & 1922 & 64.5 & 24.0 \\
\hline \multirow[t]{2}{*}{ 25OHD T3a (nmol/L) } & 1705 & 75.0 & 34.0 \\
\hline & $\mathbf{N}$ & $\%$ & \\
\hline \multicolumn{4}{|l|}{ Education level } \\
\hline Primary & 143 & 7.5 & \\
\hline Secondary & 620 & 32.3 & \\
\hline University & 1154 & 60.2 & \\
\hline \multicolumn{4}{|l|}{ Origin } \\
\hline North Europe & 1460 & 75.7 & \\
\hline America & 35 & 1.8 & \\
\hline Continental Europe & 135 & 7.0 & \\
\hline Asia & 192 & 10.0 & \\
\hline Africa & 106 & 5.5 & \\
\hline \multicolumn{4}{|l|}{ Season T1 } \\
\hline November-April & 734 & 38.1 & \\
\hline May-October & 1194 & 61.9 & \\
\hline Gestational diabetes mellitus & 11 & 0.6 & \\
\hline Large for gestational age & 40 & 2.2 & \\
\hline
\end{tabular}

$\mathrm{T}$, trimester; 25OHD, 25-hydroxyvitamin D; BMI, body mass index.

Table 2

Linear regression analysis of the association between first trimester 25-hydroxyvitamin D and blood glucose. ${ }^{a}$

\begin{tabular}{|c|c|c|c|}
\hline & \multicolumn{2}{|c|}{ Unstandardized Coefficients } & \multirow[t]{2}{*}{ P-value } \\
\hline & $\mathrm{B}$ & Standard error & \\
\hline \multicolumn{4}{|l|}{ 250HD T1 } \\
\hline \multicolumn{4}{|l|}{$<30 \mathrm{nmol} / \mathrm{L}$ (ref) } \\
\hline $30-49.9 \mathrm{nmol} / \mathrm{L}$ & -0.245 & 0.106 & 0.021 \\
\hline $50-74.9 \mathrm{nmol} / \mathrm{L}$ & -0.273 & 0.102 & 0.008 \\
\hline$\geq 75 \mathrm{nmol} / \mathrm{L}$ & -0.347 & 0.106 & 0.001 \\
\hline Gestational week $\mathrm{T} 1$ & -0.053 & 0.011 & $<0.001$ \\
\hline Maternal age $\mathrm{T} 1$ (years) & 0.011 & 0.005 & 0.032 \\
\hline Maternal BMI T1 $\left(\mathrm{kg} / \mathrm{m}^{2}\right)$ & 0.013 & 0.006 & 0.028 \\
\hline \multicolumn{4}{|l|}{ Season $\mathrm{T} 1$} \\
\hline \multicolumn{4}{|l|}{ May-October (ref) } \\
\hline November-April & -0.086 & 0.051 & 0.089 \\
\hline \multicolumn{4}{|l|}{ Origin } \\
\hline \multicolumn{4}{|l|}{ North European (ref) } \\
\hline Non-North European & 0.272 & 0.068 & $<0.001$ \\
\hline \multicolumn{4}{|l|}{ Education level } \\
\hline \multicolumn{4}{|l|}{ University (ref) } \\
\hline Primary & 0.229 & 0.105 & 0.029 \\
\hline Secondary & 0.020 & 0.056 & 0.723 \\
\hline
\end{tabular}

T1, trimester 1; 25OHD, 25-hydroxyvitamin D; BMI, body mass index; ref, reference category.

a Blood glucose (mmol/L) included as dependent variable.

was associated with higher odds of infant LGA.

Much of previous research on vitamin D and glucose homeostasis in pregnancy has so far examined the association between maternal vitamin D status and risk of developing GDM [14,15,19-21,25,26]. However, our results suggest that avoiding vitamin D deficiency may protect from hyperglycaemia, less severe than GDM. Such a relation has previously been recognised in mid-pregnancy among non-diabetic pregnant women $[14,15]$, whereas we now show this association in early pregnancy. For example, women in first trimester with $25 \mathrm{OHD} \geq 75 \mathrm{nmol} / \mathrm{L}$ had $0.35 \mathrm{mmol} / \mathrm{L}$ lower blood glucose than
Table 3

Mixed models analysis of first trimester 25-hydroxyvitamin D and blood glucose trajectory ${ }^{\mathrm{a}}$ during pregnancy.

\begin{tabular}{|c|c|c|c|c|c|}
\hline & \multirow[t]{2}{*}{ Estimate } & \multirow[t]{2}{*}{$\begin{array}{l}\text { Standard } \\
\text { error }\end{array}$} & \multirow[t]{2}{*}{$\mathrm{P}$-value } & \multicolumn{2}{|c|}{$\begin{array}{l}\text { 95\% Confidence } \\
\text { Interval }\end{array}$} \\
\hline & & & & $\begin{array}{l}\text { Lower } \\
\text { Bound }\end{array}$ & $\begin{array}{l}\text { Upper } \\
\text { Bound }\end{array}$ \\
\hline $\begin{array}{l}\text { Intercept } \\
\text { 250HD T1 } \\
\quad<30 \mathrm{nmol} / \mathrm{L} \\
\quad \text { (ref) }\end{array}$ & 4.924 & 0.164 & $<0.001$ & 4.603 & 5.245 \\
\hline $30-49.9 \mathrm{nmol} / \mathrm{L}$ & -0.129 & 0.068 & 0.056 & -0.262 & 0.003 \\
\hline $50-74.9 \mathrm{nmol} / \mathrm{L}$ & -0.086 & 0.065 & 0.183 & -0.213 & 0.041 \\
\hline$\geq 75 \mathrm{nmol} / \mathrm{L}$ & -0.153 & 0.067 & 0.023 & -0.285 & -0.021 \\
\hline $\begin{array}{l}\text { Gestational week } \\
\text { T1 }\end{array}$ & -0.036 & 0.007 & $<0.001$ & -0.050 & -0.022 \\
\hline $\begin{array}{l}\text { Maternal age } \\
\text { (years) }\end{array}$ & 0.008 & 0.003 & 0.020 & 0.001 & 0.014 \\
\hline $\begin{array}{l}\text { Maternal BMI T1 } \\
\left(\mathrm{kg} / \mathrm{m}^{2}\right)\end{array}$ & 0.021 & 0.004 & $<0.001$ & 0.013 & 0.028 \\
\hline $\begin{array}{l}\text { Season T1 } \\
\text { May-October } \\
\text { (ref) }\end{array}$ & & & & & \\
\hline $\begin{array}{l}\text { November-April } \\
\text { Education level } \\
\text { University (ref) }\end{array}$ & 0.012 & 0.032 & 0.694 & -0.050 & 0.075 \\
\hline Primary & 0.119 & 0.066 & 0.070 & -0.010 & 0.248 \\
\hline Secondary & -0.010 & 0.035 & 0.766 & -0.079 & 0.058 \\
\hline $\begin{array}{l}\text { Origin } \\
\text { North European } \\
\text { (ref) }\end{array}$ & & & & & \\
\hline $\begin{array}{l}\text { Non-North } \\
\text { European }\end{array}$ & 0.285 & 0.042 & $<0.001$ & 0.202 & 0.368 \\
\hline
\end{tabular}

T1, trimester 1; 25OHD, 25-hydroxyvitamin D; BMI, body mass index; ref, reference category.

${ }^{\text {a }}$ Blood glucose trajectory (mmol/L) as dependent variable, included glucose concentrations at T1, T2, T3a and T3b.

vitamin D deficient women. Interestingly, the HAPO study showed that increasing blood glucose levels, less severe than those found in overt diabetes, are related to clinically important perinatal disorders [3]. An increase of $0.4 \mathrm{mmol} / \mathrm{L}$ in fasting glucose corresponded to significantly higher odd ratios of serious maternal and neonatal outcomes; e.g. neonate birthweight $>90$ th centile, and primary caesarean delivery. Thus, the effect estimate that we have found where avoidance of vitamin D deficiency was related to lower levels of maternal blood glucose within what is currently considered non-diabetic ranges still may be of clinical relevance. This indicate the need to study the possible treatment effects of vitamin D already in early pregnancy on gestational glucose control in early pregnancy and throughout pregnancy.

Large longitudinal studies addressing the impact of gestation on vitamin D metabolism are scarce and we are aware of no study that has examined longitudinal changes in vitamin D metabolism in relation to gestational blood glucose trajectory. Previous findings from the GraviD cohort showed a significant increase of approximately $10 \mathrm{nmol} / \mathrm{L}$ in 25OHD concentration from early to late gestation [10]. This is consistent with other studies $[27,28]$. Glucose metabolism in pregnancy has been found to follow a similar pattern whereby increasing glycaemia is observed from early pregnancy, becoming more apparent in the second trimester and progressively to term [29]. It is biologically plausible that changes in vitamin D metabolism may predict changes in gestational glucose metabolism [11-13], but we did not find that 25OHD trajectory was not associated with glucose trajectory.

It is well-established that mothers with increasing glycaemia are at a higher risk of giving birth to LGA neonates [3,30]. Previous findings relating to vitamin D status and infant size at delivery are conflicting $[31,32]$. However, given its observed effects on maternal glucose control, one might expect poor vitamin D status to be associated with increased risk of LGA infants. Yet our study found higher rather than 
Table 4

Mixed models analysis of 25-hydroxyvitamin D trajectory ${ }^{\mathrm{b}}$ and blood glucose trajectory $^{\mathrm{a}}$ during pregnancy.

\begin{tabular}{|c|c|c|c|c|c|}
\hline & \multirow[t]{2}{*}{ Estimate } & \multirow[t]{2}{*}{$\begin{array}{l}\text { Standard } \\
\text { error }\end{array}$} & \multirow[t]{2}{*}{ P-value } & \multicolumn{2}{|c|}{$\begin{array}{l}95 \% \text { Confidence } \\
\text { Interval }\end{array}$} \\
\hline & & & & $\begin{array}{l}\text { Lower } \\
\text { Bound }\end{array}$ & $\begin{array}{l}\text { Upper } \\
\text { Bound }\end{array}$ \\
\hline Intercept & 4.907 & 0.162 & $<0.001$ & 4.589 & 5.225 \\
\hline $\begin{array}{l}\text { 250HD trajectory } \\
(\mathrm{nmol} / \mathrm{L})\end{array}$ & -0.001 & 0.001 & 0.295 & -0.002 & 0.001 \\
\hline $\begin{array}{l}\text { Gestational week } \\
\text { T1 }\end{array}$ & -0.041 & 0.007 & $<0.001$ & -0.056 & -0.027 \\
\hline $\begin{array}{l}\text { Maternal age T1 } \\
\text { (years) }\end{array}$ & 0.008 & 0.003 & 0.016 & 0.001 & 0.015 \\
\hline $\begin{array}{l}\text { Maternal BMI T1 } \\
\left(\mathrm{kg} / \mathrm{m}^{2}\right)\end{array}$ & 0.020 & 0.004 & $<0.001$ & 0.013 & 0.028 \\
\hline \multicolumn{6}{|l|}{$\begin{array}{l}\text { May-October } \\
\text { (ref) }\end{array}$} \\
\hline \multicolumn{6}{|l|}{$\begin{array}{l}\text { University level } \\
\text { (ref) }\end{array}$} \\
\hline Primary level & 0.145 & 0.066 & 0.028 & 0.015 & 0.276 \\
\hline Secondary level & -0.026 & 0.035 & 0.472 & -0.095 & 0.044 \\
\hline $\begin{array}{l}\text { Origin } \\
\text { North European } \\
\quad \text { (ref) }\end{array}$ & & & & & \\
\hline $\begin{array}{l}\text { Non-North } \\
\text { European }\end{array}$ & 0.306 & 0.041 & $<0.001$ & 0.226 & 0.386 \\
\hline
\end{tabular}

T1, trimester 1; 25OHD, 25-hydroxyvitamin D; BMI, body mass index; ref, reference category.

${ }^{a}$ Blood glucose trajectory (mmol/L) as dependent variable, included concentrations at $\mathrm{T} 1, \mathrm{~T} 2, \mathrm{~T} 3 \mathrm{a}$ and $\mathrm{T} 3 \mathrm{~b}$.

b 25OHD trajectory (nmol/L) include 25OHD measured in T1 and T3a, along with the mean of T1 and T3a as a proxy for T2. T3b is a duplicate of T3a.

Table 5

Logistic regression analysis of 25-hydroxyvitamin D in late pregnancy and the odds of infant large for gestational age.

\begin{tabular}{lllll}
\hline & B & Standard error & P-value & Odds ratio \\
\hline 25OHD T3 (nmol/L) & 0.006 & 0.003 & 0.032 & 1.006 \\
Gestational week T1 & -0.178 & 0.040 & $<0.001$ & 0.837 \\
Maternal age T1 (years) & 0.055 & 0.019 & 0.004 & 1.056 \\
$\quad$ Maternal BMI T1 (kg/m ${ }^{2}$ ) & 0.095 & 0.018 & $<0.001$ & 1.100 \\
$\quad$ Education level & & & 0.701 & \\
$\quad$ University (ref) & & & 0.694 & 0.852 \\
$\quad$ Primary & -0.160 & 0.406 & 0.417 & 0.851 \\
$\quad$ Secondary & -0.162 & 0.199 & & \\
$\quad$ Origin & & & & \\
$\quad$ North European (ref) & -0.275 & 0.256 & 0.282 & 0.759 \\
$\quad$ Non-North European & & & & \\
$\quad$ Season T3 & & & \\
$\quad$ May-October (ref) & 0.122 & 0.193 & 0.529 & 1.130 \\
$\quad$ November-April & & &
\end{tabular}

T1, trimester 1; T3, trimester 3; 25OHD, 25-hydroxyvitamin D; BMI, body mass index; ref, reference category.

lower vitamin D status was associated with higher odds of LGA infants. The exact effects of vitamin D deficiency coupled with increasing maternal glucose on foetal growth remains a largely unknown mechanism that requires further exploration.

One strength is that this study include the large prospective cohort with participants from multiple ethnic groups and a comparable study sample to the general Swedish population in terms of BMI, ethnicity and parity [33]. Another strength is the use of the liquid chromatography-mass spectrometry method used to assess $25 \mathrm{OHD}$ concentration, since it is considered the gold standard for valid estimation of vitamin D status. The determination of $250 H D$ concentrations in early pregnancy served to explore the temporal relationship between maternal vitamin D deficiency and subsequent blood glucose levels in the first, second and third trimesters. To the best of the author's knowledge, no other studies have prospectively assessed the influence of early vitamin D status on blood glucose trajectory in the pregnant population or have examined the relation between vitamin D and glucose trajectory in pregnancy, respectively.

It is a limitation that only random blood glucose levels were available as a surrogate measure of glucose homeostasis in the pregnant state. Random blood glucose may not perfectly reflect overall glucose control. Furthermore, it is possible that the observed negative associations between maternal vitamin D status and blood glucose reflect the impact of co-factors of risk that were not included in this study. The confounding effects of inflammation, physical activity, visceral adiposity, overall nutritional status and water retention were not included in the study and thus residual confounding may exist.

\section{Conclusion}

In conclusion, the results from this study indicate that higher maternal vitamin D in early pregnancy associates with lower blood glucose in early pregnancy and blood glucose trajectory throughout pregnancy. Higher 25OHD in late pregnancy was associated with higher odds of LGA at birth. Thus, further well-designed observational and interventional studies are required to determine the explicit effect of vitamin D on gestational glucose metabolism.

\section{Funding}

This work was supported by the Swedish Research Council for Health, Working Life and Welfare (Dnr 2012-0793, 2012), The Healthcare sub-committee, Region Västra Götaland (Hälso- och sjuvårdsutskottet) (VG FOU REG-229331, 2011; and VG FOU REG388201, 2013), Linnea and Josef Carlsson Foundation (2016 and 2017), Queen Silvia's Jubilee Fund (2016).

\section{Acknowledgements}

The authors would like to acknowledge the women participating in the study, as well as the midwives and nurses whose contributions were pivotal in the realization of the study.

\section{References}

[1] L. Guariguata, U. Linnenkamp, J. Beagley, D.R. Whiting, N.H. Cho, Global estimates of the prevalence of hyperglycaemia in pregnancy, Diabetes Res. Clin. Pract. 103 (2) (2014) 176-185.

[2] A. Vambergue, I. Fajardy, Consequences of gestational and pregestational diabetes on placental function and birth weight, World J. Diabetes 2 (11) (2011) 196-203.

[3] B.E. Metzger, L.P. Lowe, A.R. Dyer, E.R. Trimble, U. Chaovarindr, D.R. Coustan, et al., Hyperglycemia and adverse pregnancy outcomes, N. Engl. J. Med. 358 (19) (2008) 1991-2002.

[4] P.S. George, E.R. Pearson, M.D. Witham, Effect of vitamin D supplementation on glycaemic control and insulin resistance: a systematic review and meta-analysis, Diabet Med. 29 (8) (2012) e142-50.

[5] H.H. Burris, M.S.L. Rifas-Shiman, K. Kleinman, A.A. Litonjua, S.Y. Huh, J.W. RichEdwards, et al., Vitamin D deficiency in pregnancy and gestational diabetes, Am. J. Obstet. Gynecol. 207 (3) (2012) 182.e1-.e8.

[6] K.M. Seamans, K.D. Cashman, Existing and potentially novel functional markers of vitamin D status: a systematic review, Am. J. Clin. Nutr. 89 (6) (2009) 1997s-2008s.

[7] M. Kiely, A. Hemmingway, K.M. O'Callaghan, Vitamin D in pregnancy: current perspectives and future directions, Ther. Adv. Musculoskelet Dis. 9 (6) (2017) 145-154.

[8] Institute of Medicine Committee to Review Dietary Reference Intakes for Vitamin D and Calcium, The national academies collection: reports funded by national institutes of health, in: A.C. Ross, C.L. Taylor, A.L. Yaktine, H.B. Del Valle (Eds.), Dietary Reference Intakes for Calcium and Vitamin D, National Academies Press (US). National Academy of Sciences, Washington (DC), 2011.

[9] Nordic Council of Ministers, Nordic Nutrition Recommendations, 5th edition, (2012), p. 2014.

[10] L. Barebring, I. Schoenmakers, A. Glantz, L. Hulthen, A. Jagner, J. Ellis, et al., 
Vitamin D Status during pregnancy in a multi-ethnic population-representative Swedish cohort, Nutrients 8 (10) (2016).

[11] S.A. Clark, W.E. Stumpf, M. Sar, Effect of 1,25 dihydroxyvitamin D3 on insulin secretion, Diabetes 30 (5) (1981) 382

[12] J.A. Alvarez, A. Ashraf, Role of vitamin D in insulin secretion and insulin sensitivity for glucose homeostasis, Int. J. Endocrinol. (2010) (2010) 351385.

[13] F. Haidari, M.-T. Jalali, N. Shahbazian, M.-H. Haghighizadeh, E. Azadegan, Comparison of serum levels of vitamin D and inflammatory markers between women with gestational diabetes mellitus and healthy pregnant control, J. Fam. Reprod. Health. 10 (1) (2016) 1-8.

[14] Z. Maghbooli, A. Hossein-nezhad, F. Karimi, A.R. Shafaei, B. Larijani, Correlation between vitamin D3 deficiency and insulin resistance in pregnancy, Diabetes Metab. Res. Rev. 24 (1) (2007) 27-32.

[15] R.J. Clifton-Bligh, P. McElduff, A. McElduff, Maternal vitamin D deficiency, ethnicity and gestational diabetes, Diabet Med. 25 (6) (2008) 678-684.

[16] F. Aghajafari, T. Nagulesapillai, P.E. Ronksley, S.C. Tough, M. O’Beirne, D.M. Rabi, Association between maternal serum 25-hydroxyvitamin D level and pregnancy and neonatal outcomes: systematic review and meta-analysis of observational studies, BMJ 346 (2013) f1169.

[17] S.Q. Wei, H.P. Qi, Z.C. Luo, W.D. Fraser, Maternal vitamin D status and adverse pregnancy outcomes: a systematic review and meta-analysis, J. Matern. Fetal. Neonatal. Med. 26 (9) (2013) 889-899.

[18] M.X. Zhang, G.T. Pan, J.F. Guo, B.Y. Li, L.Q. Qin, Z.L. Zhang, Vitamin D deficiency increases the risk of gestational diabetes mellitus: a meta-analysis of observational studies, Nutrients. 7 (10) (2015) 8366-8375.

[19] M. Lu, Y. Xu, L. Lv, M. Zhang, Association between vitamin D status and the risk of gestational diabetes mellitus: a meta-analysis, Arch. Gynecol. Obstet. 293 (5) (2016) 959-966.

[20] M. Lacroix, M.C. Battista, M. Doyon, G. Houde, J. Menard, J.L. Ardilouze, et al., Lower vitamin D levels at first trimester are associated with higher risk of developing gestational diabetes mellitus, Acta Diabetol. 51 (4) (2014) 609-616.

[21] S. Park, H.-K. Yoon, H.-M. Ryu, Y.J. Han, S.W. Lee, B.K. Park, et al., Maternal vi tamin D deficiency in early pregnancy Is not associated with gestational diabetes mellitus development or pregnancy outcomes in Korean pregnant women in a prospective study, J. Nutr. Sci. Vitaminol. (Tokyo) 60 (4) (2014) 269-275.

[22] F.J. Schneuer, C.L. Roberts, C. Guilbert, J.M. Simpson, C.S. Algert, A.Z. Khambalia, et al., Effects of maternal serum 25-hydroxyvitamin D concentrations in the first trimester on subsequent pregnancy outcomes in an Australian population, Am. J. Clin. Nutr. 99 (2) (2014) 287-295.

[23] L. Parlea, I.L. Bromberg, D.S. Feig, R. Vieth, E. Merman, L.L. Lipscombe, Association between serum 25-hydroxyvitamin D in early pregnancy and risk of gestational diabetes mellitus, Diabet. Med. 29 (7) (2012) e25-32.

[24] D.L. Arnold, D.A. Enquobahrie, C. Qiu, J. Huang, N. Grote, A. VanderStoep, et al., Early pregnancy maternal vitamin D concentrations and risk of gestational diabetes mellitus, Paediatr. Perinat. Epidemiol. 29 (3) (2015) 200-210.

[25] A.M. Baker, S. Haeri, C.A. Camargo Jr., A.M. Stuebe, K.A. Boggess, First-trimester maternal vitamin D status and risk for gestational diabetes (GDM) a nested casecontrol study, Diabetes Metab. Res. Rev. 28 (2) (2012) 164-168.

[26] L.M. De-Regil, C. Palacios, L.K. Lombardo, J.P. Pena-Rosas, Vitamin D supplementation for women during pregnancy, Cochrane Database Syst. Rev. (1) (2016) Cd008873.

[27] J.Y. Zhang, A.J. Lucey, R. Horgan, L.C. Kenny, M. Kiely, Impact of pregnancy on vitamin D status: a longitudinal study, Br. J. Nutr. 112 (7) (2014) 1081-1087.

[28] A. Lundqvist, H. Sandstrom, H. Stenlund, I. Johansson, J. Hultdin, Vitamin D status during pregnancy: a longitudinal study in Swedish women from early pregnancy to seven months postpartum, PLoS One. 11 (3) (2016) e0150385.

[29] A.R. Angueira, A.E. Ludvik, T.E. Reddy, B. Wicksteed, W.L. Lowe, B.T. Layden, New insights into gestational glucose metabolism: lessons learned from 21st century approaches, Diabetes 64 (2) (2015) 327-334.

[30] O. Langer, R. Mazze, The relationship between large-for-gestational-age infants and glycemic control in women with gestational diabetes, Am. J. Obstet. Gynecol. 159 (6) (1988) 1478-1483.

[31] A. Rodriguez, R. Garcia-Esteban, M. Basterretxea, A. Lertxundi, C. RodriguezBernal, C. Iniguez, et al., Associations of maternal circulating 25-hydroxyvitamin D3 concentration with pregnancy and birth outcomes, BJOG 122 (12) (2015) 1695-1704.

[32] A.D. Gernand, H.N. Simhan, S. Caritis, L.M. Bodnar, Maternal vitamin D Status and small-for-gestational-age offspring in women at High risk for preeclampsia, Obstetrics Gynecol. 123 (1) (2014) 40-48.

[33] Swedish National Board of Health and Welfare. Sweden Pregnancies, Deliveries, and Newborn Infants 2015: National Board of Health and Welfare (Sweden); 2018 [Available from: http://ghdx.healthdata.org/record/sweden-pregnanciesdeliveries-and-newborn-infants-2015. 